\title{
Preparation of a Dmap-Catalysis Lignin Epoxide and the Study of Its High Mechanical-Strength Epoxy Resins with High-Biomass Content
}

\author{
Lingxia Song ${ }^{1,2,3,4,5}$, Yeyun Meng ${ }^{1,2}$, Peng Lv ${ }^{1,2}$, Weiqu Liu ${ }^{1, *}$ and Hao Pang ${ }^{1, *}$ \\ 1 Guangzhou Institute of Chemistry, Chinese Academy of Sciences, Guangzhou 510650, China; \\ jnssllxx@163.com (L.S.); mengyeyun15@mails.ucas.ac.cn (Y.M.); lvpengtust@163.com (P.L.) \\ 2 University of Chinese Academy of Sciences, Beijing 100049, China \\ 3 Guangdong Provincial Key Laboratory of Organic Polymer Materials for Electronics, \\ Guangzhou 510650, China \\ 4 CAS Engineering Laboratory for Special Fine Chemicals, Guangzhou 510650, China \\ 5 CASH GCC(Nanxiong) Research Institute of New Materials Co., Ltd., Nanxiong 512400, China \\ * Correspondence: liuwq@gic.ac.cn (W.L.); panghao@gic.ac.cn (H.P.)
}

check for

updates

Citation: Song, L.; Meng, Y.; Lv, P.; Liu, W.; Pang, H. Preparation of a Dmap-Catalysis Lignin Epoxide and the Study of Its High Mechanical-Strength Epoxy Resins with High-Biomass Content. Polymers 2021, 13, 750. https://doi.org/10.3390/polym 13050750

Academic Editor: Evgenia

G. Korzhikova-Vlakh

Received: 3 February 2021

Accepted: 24 February 2021

Published: 28 February 2021

Publisher's Note: MDPI stays neutral with regard to jurisdictional claims in published maps and institutional affiliations.

Copyright: (c) 2021 by the authors. Licensee MDPI, Basel, Switzerland. This article is an open access article distributed under the terms and conditions of the Creative Commons Attribution (CC BY) license (https:// creativecommons.org/licenses/by/ $4.0 /)$
Abstract: The depletion of limited petroleum resources used for the fabrication of epoxy resins calls for the development of biomass-based epoxides as promising alternatives to petroleum-derived epoxides. However, it is challenging to obtain an epoxy resin with both high lignin content and excellent mechanical performance. Herein, a 4-dimethylaminopyridine (DMAP)-lignin epoxide with a certain epoxy value and a small molecular weight is obtained by the catalysis of DMAP for the macromolecular lignin. It was discovered that compared to the prepared composite resin of benzyltriethylammonium chloride (BTEAC)-lignin epoxide, there is a better low-temperature storage modulus for the DMAP-lignin epoxide resin and its composite resins with high-biomass contents, and higher tensile strength for its composite resins. In particular, the DMAP-lignin epoxide/ bisphenol A diglycidyl ether (BADGE) (DB) composite resin with DMAP-lignin epoxide replacement of $80 \mathrm{wt} \%$ BADGE, containing up to $58.0 \mathrm{wt} \%$ the lignin epoxide, exhibits the tensile strength of $76.3 \pm 3.2 \mathrm{MPa}$. Its tensile strength is $110.2 \%$ of BTEAC-lignin epoxide/BADGE (BB) composite resins and is comparable to that of petroleum-based epoxy resins. There are good application prospects for the DB composite resin in the engineering plastics, functional composite, grouting, and other fields.

Keywords: DMAP-lignin epoxide; bio-based epoxy resin; composite resin; tensile strength

\section{Introduction}

As renewable biomass, lignin is abundant in nature and cheap to obtain. It is the second most abundant biopolymer after cellulose and the most abundant natural aromatic compound [1,2]. Nearly 50 million tons of lignin are produced each year, but only $2 \%$ are used for the production of value-added materials because of its complex construction and poor processability. With the efforts of researchers, lignin has been researched in many fields. The high carbon content in lignin can be used to prepare carbon-based supercapacitors and carbon fiber materials [3]. The phenolic hydroxyl group of lignin has a good reductivity for the synthesis of silver nanoparticles, and its macromolecular structure can be used as micro-carriers for the resulting silver nanoparticles [4]. Lignin has been transformed into polymers such as polyhydroxyalkanoates by means of microbial degradation [5,6]. Lignin as a macromolecular composed of benzene ring has been composited with petroleum-based compounds (such as resorcinol or phenol, urea, epoxy resins, and polyurethane), to improve the strength and toughness of composite resin and realize its application in the engineering field $[7,8]$. In particular, lignin, through chemical modification, can participate in the thermal curing reaction, which not only effectively improves the mechanical properties of other resins, but also realizes the partial and total 
replacement of the petroleum-based compounds, and solves the problems of the petroleum resource crisis and environmental pollution $[9,10]$.

Lignin contains a large number of active hydroxyl groups and carboxyl groups, instead of bisphenol A to prepare the epoxy compound. The obtained lignin-based epoxy compound has thermosetting properties. However, compared with bisphenol A epoxy compound, the lower content of the epoxy group and the steric hindrance for the macromolecular lignin epoxides lead to poor mechanical properties for the resin, so it is very necessary to composite with bisphenol A epoxy compound. The lignin epoxide with the macromolecular structure is introduced into the bisphenol A epoxy resin matrix and participates in the chemical crosslinking of resin. As a result, it can effectively block the crack propagation fracture of bisphenol A epoxy resin and improve the strength and toughness of resin [1,11,12]. In addition to the above advantages, lignin epoxide itself will undergo certain changes of its chemical structure during continuous thermal processing, and condensation between the lignin fragments could occur, making the resin structure more packed to increase the strength [13-15]. Daniel Jason et al. synthesized the lignin-derived epoxy prepolymers via both the mild hydrogenolysis and the epoxidation of lignin and used it to replace $25-75 \%$ of the bisphenol A diglycidyl ether equivalent, discovering increases of up to $52 \%$ in the flexural modulus and up to $38 \%$ in the flexural strength [16]. Fatemeh Ferdosian et al. used the bio-based epoxy systems as polymer matrices for manufacturing fiber-reinforced plastics (FRPs) and coatings. The tensile and flexural strengths of the prepared FRPs using bio-based epoxy composites were superior or comparable to those of the FRP with the pure bisphenol A epoxy resin [17]. Claudio Gioia et al. investigated the relationship between thermomechanical properties and the chemical structure of the well-characterized lignin-based epoxy resins. It was discovered that compared to eucalyptus-based resins, the spruce-based lignin resin results in somewhat higher modulus and higher tensile strength because of the more condensed structures [18].

The above research work is mainly about the mechanical properties of the epoxy compound composite resin with the small molecule state lignin. Namely, The lignin is degraded or refined to a small molecular weight $\left(\mathrm{M}_{\mathrm{W}}<2000 \mathrm{Da}\right)$. Then the lignin is epoxidized, and the composite resin is prepared. The epoxidation of lignin with higher molecular weight is rarely studied $\left(\mathrm{M}_{\mathrm{W}}>2000 \mathrm{Da}\right)$. The main reason is that the intermolecular etherification crosslinking (crosslinking reaction between the epoxy group and hydroxyl group) easily occurs in the lignin epoxidation reaction, leading to an obvious increase in molecular weight and a severe decrease in compatibility with bisphenol A epoxide. Therefore, it is very important to control the molecular weight of lignin $\left(\mathrm{M}_{\mathrm{w}}>2000 \mathrm{Da}\right)$ during the epoxidation and guarantee the epoxy group content.

The catalyst has a significant influence on the epoxy value and molecular weight of the reaction product $[19,20]$. For the catalysts, the selection is generally based on experimental design. There are two main methods: the one-step catalytic method of sodium hydroxide solution and the two-step catalytic method of ammonium salt-sodium hydroxide phase transfer [21,22]. The one-step method easily causes the etherification crosslinking reaction between molecules, resulting in the obvious increase of molecular weight. The two-step method, as a common method, can effectively promote the epoxidation of lignin and control the molecular weight effect. Herein, we found that 4-dimethylaminopyridine (DMAP) can be used to epoxidize lignin, with the catalytic effect comparable to that of quaternary ammonium salt catalyst, this can achieve the epoxidation of lignin and control the molecular weight of lignin epoxides.

In this paper, DMAP-lignin epoxide was synthesized by catalysis of DMAP, and its molecular weight and epoxy value were evaluated. The mechanical properties of amine-cured DMAP-lignin epoxy resin and its composite resin with bisphenol A diglycidyl ether (BADGE) were studied. In order to better illustrate DMAP's catalytic effect and its performance advantage as an alternative to the BADGE, the benzyltriethylammonium chloride (BTEAC)-lignin epoxide was compared with DMAP-lignin epoxide in terms of molecular features and resin properties. 


\section{Experimental}

\subsection{Materials and Chemicals}

Lignin was purchased from Yanghai Environmental Protection material Co., Ltd. (Alibaba, Jinan, China). The lignin was from the straw plant. The parameters obtained for the purchased lignin are given in Table 1, and the typical structural units of lignin are described in Figure S1 [23].

Table 1. The parameters obtained for the as-purchased lignin.

\begin{tabular}{ccccccc}
\hline Type & $\mathbf{M}_{\mathbf{n}}$ & $\mathbf{M}_{\mathbf{w}}$ & $\mathbf{\Xi}$ & $\begin{array}{c}\text { ph-OH Content } \\
\text { (mmol/g) }\end{array}$ & $\begin{array}{c}\text {-COOH Content } \\
\text { (mmol/g) }\end{array}$ & $\begin{array}{c}\text { Ratio of G } \\
\text { to S (G/S) }\end{array}$ \\
\hline Softwood lignin & 2827 & 3153 & 1.12 & 3.05 & 1.71 & $>50 \%$ \\
\hline
\end{tabular}

Note: $M_{n}$ is the number-average molecular weight, $M_{w}$ is the weight-average molecular weight, $Đ$ represents molecular weight distribution, ph-OH denotes the phenolic hydroxyl group, $-\mathrm{COOH}$ is the carboxyl group, $\mathrm{G}$ and $\mathrm{S}$ represent guaiacyl and syringyl, respectively.

$\mathrm{ECH}(99.5 \%), \mathrm{NaOH}(99.5 \%)$, and dimethyl sulfoxide (DMSO, 99.5\%) were supplied by Aladdin Biochemical Technology Co., Ltd (Shanghai, China). DMAP (99.5\%), triethylene teramine (TETA, 70.0\%), BTEAC (99.5\%), DMF $(99.0 \%)$, and BDDGE $(95.0 \%)$ were obtained from Shanghai Macklin Biochemical Co., Ltd. (Shanghai, China). BADGE (85\%) was purchased from Sigma-Aldrich Trading Co., Ltd. (Shanghai, China). All of the chemicals were of analytical grade and used as received unless stated otherwise.

\subsection{Preparation of Lignin Epoxides}

A given amount of lignin $(4.80 \mathrm{~g})$, DMAP $(3.9 \mathrm{mmol}, 0.48 \mathrm{~g})$, and DMSO $(50 \mathrm{~mL})$ were placed in a round-bottom flask $(250 \mathrm{~mL})$ equipped with a thermometer, a stirrer, and a condenser. The mixture was heated to $117^{\circ} \mathrm{C}$ under $\mathrm{N}_{2}$ bubbling conditions and was stirred for $30 \mathrm{~min}$. Afterward, $\mathrm{ECH}(100 \mathrm{~mL}, 1.27 \mathrm{~mol})$ was added while holding the reaction at $117^{\circ} \mathrm{C}$ for $180 \mathrm{~min}$. Then, the reactants were cooled to $70^{\circ} \mathrm{C}$ before a $\mathrm{NaOH}$ aqueous solution $(5 \mathrm{M}, 18 \mathrm{~mL})$ was added at the speed of $0.1 \mathrm{~mL} / \mathrm{min}$ over a $180 \mathrm{~min}$ duration using a peristaltic pump. Subsequently, the reaction mixture was cooled to room temperature and was followed by transferring it to a beaker $(500 \mathrm{~mL})$. For the removal of the watersoluble impurities, including the catalyst, the deionized water $(350 \mathrm{~mL})$ was poured into the beaker, and intensely stirred. The mixture was allowed to stand for a sufficient length of time until a brown oily mixture formed at the bottom of the aqueous solution, then the water phase of the separated liquids was decanted. This process was repeated thrice. Next, dichloromethane $(50 \mathrm{~mL})$ was poured into the beaker under adequate agitation. The product was separated out of the mixture containing a small amount of residual water, which was then allowed to stand until the emergence of the layered liquids. The water and insoluble solid layers were discarded, and the deep brown dichloromethane solution, with the product dissolved, was obtained. In order to facilitate the next purification of the product, $30 \mathrm{~mL}$ of dichloromethane was removed from the dichloromethane solution by rotary evaporation. The dichloromethane solution was added drop-by-drop to ethyl acetate $(200 \mathrm{~mL})$ under magnetic agitation, and a brown precipitate was separated out of ethyl acetate. By filtering and blow-drying the brown precipitate at room temperature, the DMAP-lignin epoxide sample was finally obtained. The prepared sample was stored in DMF, with a solid content of $55-65 \%$, to avoid an intermolecular crosslinking reaction that would decrease its solubility.

The BTEAC-lignin epoxide was prepared according to a similar procedure as for the synthesis of the DMAP-lignin epoxide sample, using lignin ( $4.80 \mathrm{~g})$, BTEAC ( $3.9 \mathrm{mmol}, 0.89 \mathrm{~g})$, $\mathrm{DMSO}(50 \mathrm{~mL}), \mathrm{ECH}(100 \mathrm{~mL}, 1.27 \mathrm{~mol})$, and $\mathrm{NaOH}(5 \mathrm{M}, 18 \mathrm{~mL})$ as the starting materials. 


\subsection{Preparation of Epoxy Resins}

2.3.1. Preparation of the DMAP-Lignin Epoxide Resin, BTEAC-Lignin Epoxide Resin, and BADGE Resin

Into the DMF solution of the epoxide, a certain amount of the curing agent (i.e., TETA) was dropwise added while keeping agitation for homogeneous mixing at room temperature. The mixture was allowed to stand until the bubbles disappeared and was then cast into a polytetrafluoroethylene (PTFE)-lined mold to cure in an air-circulating oven. The following curing procedure was sequentially adopted: heating at $70^{\circ} \mathrm{C}$ for $24 \mathrm{~h}, 120^{\circ} \mathrm{C}$ for $4 \mathrm{~h}$, and finally at $180^{\circ} \mathrm{C}$ for $4 \mathrm{~h}$. The epoxy resin sample was produced after demolding at room temperature. Different kinds of epoxy resin samples were prepared according to the recipe provided in Table 2.

Table 2. The specifications of different types of epoxy resins: the 4-dimethylaminopyridine (DMAP)lignin epoxide resin, benzyltriethylammonium chloride (BTEAC)-lignin epoxide resin, and bisphenol A diglycidyl ether (BADGE) resin.

\begin{tabular}{ccccc}
\hline \multirow{2}{*}{ Sample } & $\begin{array}{c}\text { DMAP-Lignin } \\
\text { Epoxide }\end{array}$ & $\begin{array}{c}\text { BTEAC-Lignin } \\
\text { Epoxide }\end{array}$ & BADGE & TETA \\
\cline { 2 - 5 } & $\mathbf{( g )}$ & $\mathbf{( g )}$ & $\mathbf{( g )}$ & $\mathbf{( g )}$ \\
\hline DMAP-lignin epoxide resin & 22.00 & - & - & 3.00 \\
BTEAC-lignin epoxide resin & - & 22.00 & - & 3.00 \\
BADGE resin & - & - & 22.00 & 3.00 \\
\hline
\end{tabular}

\subsubsection{Preparation of the Lignin Epoxide/BADGE Composite Epoxy Resin}

The DMF solution of the lignin epoxide, BDDGE, and BADGE were successively dissolved in DMF solvent $(3.5 \mathrm{~mL})$; and the DMF solution with well-dissolved epoxides was obtained by adequate stirring. The amount of each added component is provided in Table 3. To promote the crosslinking and curing, we volatilized a certain amount of DMF, which was determined by the weight loss of the beaker loaded with the DMF solution during heating. After the reaction was continuously heated at $80^{\circ} \mathrm{C}$ until $3.0 \mathrm{~mL}$ DMF was volatilized, the heating was stopped, and the reaction mixture was naturally cooled to room temperature. A mixture of epoxides with good fluidity was obtained. After that, the amine-based curing agent (TETA) was homogenized to the mixture by stirring; and the sequential curing procedures were adopted. Specifically, the mixture was first cured at room temperature until it was immobile, followed by heating at $70^{\circ} \mathrm{C}$ for $12 \mathrm{~h}, 120^{\circ} \mathrm{C}$ for $8 \mathrm{~h}$, and, finally, $150^{\circ} \mathrm{C}$ for $6 \mathrm{~h}$. The lignin epoxide/BADGE composite epoxy resin was obtained after demolding at room temperature.

Table 3. The formulation adopted for the preparation of a series of the lignin epoxide/BADGE composite resin samples with different ratios of the lignin epoxide to BADGE.

\begin{tabular}{cccccc}
\hline \multirow{2}{*}{ Sample } & $\begin{array}{c}\text { DMAP-Lignin } \\
\text { Epoxide }\end{array}$ & $\begin{array}{c}\text { BTEAC-Lignin } \\
\text { Epoxide }\end{array}$ & BADGE & BDDGE & TETA \\
\cline { 2 - 6 } & $\mathbf{( g )}$ & $\mathbf{( g )}$ & $\mathbf{( g )}$ & $\mathbf{( g )}$ & $\mathbf{( g )}$ \\
\hline DB0/BB0 & 0.00 & 0.00 & 5.00 & 1.25 & 0.65 \\
DB10 & 0.50 & - & 4.50 & 1.25 & 0.65 \\
DB20 & 1.00 & - & 4.00 & 1.25 & 0.65 \\
DB40 & 2.00 & - & 3.00 & 1.25 & 0.65 \\
DB60 & 3.00 & - & 2.00 & 1.25 & 0.65 \\
DB80 & 4.00 & 0.50 & 1.00 & 1.25 & 0.65 \\
BB10 & - & 1.00 & 4.50 & 1.25 & 0.65 \\
BB20 & - & & & 1.25 & 0.65 \\
\hline
\end{tabular}


Table 3. Cont.

\begin{tabular}{cccccc}
\hline \multirow{2}{*}{ Sample } & $\begin{array}{c}\text { DMAP-Lignin } \\
\text { Epoxide }\end{array}$ & $\begin{array}{c}\text { BTEAC-Lignin } \\
\text { Epoxide }\end{array}$ & BADGE & BDDGE & TETA \\
\cline { 2 - 6 } & $\mathbf{( g )}$ & $\mathbf{( g )}$ & $\mathbf{( g )}$ & $\mathbf{( g )}$ & $\mathbf{( g )}$ \\
\hline BB40 & - & 2.00 & 3.00 & 1.25 & 0.65 \\
BB60 & - & 3.00 & 2.00 & 1.25 & 0.65 \\
BB80 & - & 4.00 & 1.00 & 1.25 & 0.65 \\
\hline
\end{tabular}

Note: DB10 represents the prepared DMAP-lignin epoxide/BADGE resin with $10 \mathrm{wt} \%$ DMAP-lignin epoxide and $90 \mathrm{wt} \%$ BADGE, respectively, while the other samples are named accordingly based on the weight percentage of lignin epoxide.

\subsection{Characterizations}

Fourier transform infrared spectroscopy (FTIR) was adopted to analyze the functional groups of various samples using an infrared spectrometer (Bruker Tensor 27, Karlsruhe, Germany), with a scanning range of $400-4000 \mathrm{~cm}^{-1}$ and scanning resolution of $4 \mathrm{~cm}^{-1}$. The molecular structure of the prepared samples was also investigated using a ${ }^{1} \mathrm{H}$ nuclear magnetic resonance $\left({ }^{1} \mathrm{H}\right.$ NMR) spectrometer (Avance III 400, Bruker Co., Ltd., Karlsruhe, Germany). For the ${ }^{1} \mathrm{H}$ NMR test, the DMSO-d6 $(0.6 \mathrm{~mL})$ was adopted as the solvent, while $p$-nitrobenzaldehyde $(p-\mathrm{NBD}, 5.0 \mathrm{mg})$ was used as the internal standard. The mass of the specimen for the ${ }^{1} \mathrm{H}$ NMR test was $25.0 \mathrm{mg}$. The locations of the ${ }^{1} \mathrm{H}$ NMR peaks associated with the solvent were found at $\delta_{H} 2.46-2.54 \mathrm{ppm}$, while those of the internal standard were observed at $\delta_{H} 8.10-8.20 \mathrm{ppm}, 8.30-8.50 \mathrm{ppm}$, and $10.10-10.20 \mathrm{ppm}$.

\subsection{Analysis of the Lignin Epoxidation}

Based on the ${ }^{1} \mathrm{H}$ NMR spectra, the epoxy values were calculated by a comparison between the peak area of hydrogen arising from the epoxy group and the peak area indexed to the internal standard ( $p$-NBD, $\delta_{H} 10.10-10.20 \mathrm{ppm}$ ) [24]. The area in the chemical shift range of $2.60-2.90 \mathrm{ppm}$ is the peak area of hydrogen arising from the epoxy group [25,26].

\subsection{Molecular Weight Analysis}

Gel permeation chromatography (GPC) was employed to measure the molecular weight of the prepared samples using a Waters chromatograph (Milford, MA, USA) equipped with a Waters 2414 refractive index detector. The polymethyl methacrylate (PMMA) was adopted as the standard specimen and DMF as eluent. A DMF solution of the sample $(3 \mathrm{mg} / \mathrm{mL})$ was prepared, and a portion $(50 \mathrm{uL})$ was withdrawn and was passed through a single PLgel MIXED-C column after being filtered with a $0.22 \mu \mathrm{m}$ permeable membrane. The samples were then eluted using DMF at an elution rate of $1 \mathrm{~mL} / \mathrm{min}$ and a column temperature of $35^{\circ} \mathrm{C}$. The molecular weight was finally measured by a comparison between the eluted sample and the standard sample.

\subsection{Test on the Mechanical, Thermomechanical, and Thermal Performance}

Dynamic mechanical analysis (DMA) was performed using a DMA+300 analyzer (Metravib Co., Ltd., Limonest, France); and the storage modulus, loss modulus, and Tan $\delta$ were measured for the prepared samples. The single cantilever method was adopted for the DMA test on the sample with a size of $40.0 \times 8.0 \times 3.0 \mathrm{~mm}^{3}$, with a temperature ramp of -80 to $200{ }^{\circ} \mathrm{C}$ at a heating rate and vibration frequency of $3{ }^{\circ} \mathrm{C} / \mathrm{min}$ and $1 \mathrm{~Hz}$.

The calculation of the crosslinking density was carried out according to the following method: the temperature at the maximum of the peak on the curve of Tan $\delta$ vs. temperature was assigned to the glass transition temperature $\left(T_{g}\right)$, and according to the classical rubber elasticity theory, the crosslinking density of the thermosetting epoxy resin was calculated by Equation (1) [1,27].

$$
\rho=\mathrm{E}^{\prime} / 3 \mathrm{RT}
$$


where $E^{\prime}$ represents the storage modulus of the sample at the temperature of $T_{g}+30^{\circ} \mathrm{C}$, and $R$ and $T$ denote gas constant and absolute temperature of the sample at the temperature of $T_{g}+30^{\circ} \mathrm{C}$, respectively.

The tensile test was conducted using the $10 \mathrm{kN}$ universal testing machine (Reger Co., Ltd., Shenzhen, China) according to the ASTM D638-2003 standard. The specimens were prepared in a dumbbell shape (with the width, thickness, and fixed length of 4.0, 2.0 , and $25.0 \mathrm{~mm}$, respectively), and the tension loading rate was set to $5 \mathrm{~mm} / \mathrm{min}$. Each sample was tested in a parallel fashion four times, and the average value was reported in this paper.

The fractured cross-sectional morphologies of the samples after finishing the tensile test were observed using an S-4800 scanning electron microscope (SEM, Hitachi Co., Ltd., Tokyo, Japan). Before the SEM observation, a thin layer of gold was splattered onto the sample surface.

The thermal stability of the sample was evaluated using a TGA Q500 thermogravimetric analyzer (TA Co., Ltd., New Castle, DE, USA), with a temperature ramp of 30 to $800{ }^{\circ} \mathrm{C}$ at the heating rate of $10^{\circ} \mathrm{C} / \mathrm{min}$. Thermal weight losses were measured under both $\mathrm{N}_{2}$ and air atmospheres at a gas flow rate of $50 \mathrm{~mL} / \mathrm{min}$.

\section{Results and Discussion}

\subsection{Synthesis and Characterization of the Lignin Epoxides}

Figure 1 shows the structure of the pristine lignin and the lignin epoxides examined by the FTIR spectrum. There are similar characteristic absorption bands before and after the epoxidation of lignin. The assignments for the peaks of lignin are listed in Table 4 [28]. The absorption band at $3450 \mathrm{~cm}^{-1}$ for the lignin, which can be assigned to the $-\mathrm{OH}$ stretching vibrations, becomes weakened in the DMAP-lignin epoxide, and the absorption peaks of $\mathrm{C}=\mathrm{O}$ stretching at $1700 \mathrm{~cm}^{-1}$ and $\mathrm{C}-\mathrm{O}$ stretching at $1260 \mathrm{~cm}^{-1}$ for lignin disappear. While the $\mathrm{C}=\mathrm{O}$ stretching peak at $1710 \mathrm{~cm}^{-1}$ is attributed to the ester group and the $\mathrm{C}-\mathrm{O}$ stretching peak at $1248 \mathrm{~cm}^{-1}$ representing the phenoxy group appear, and the absorption peak at $910 \mathrm{~cm}^{-1}$ appears corresponding to the epoxy group. The changes of active groups and appearance of the epoxy group are consistent with the characterization of Chizuru Sasaki et al. for the lignin epoxide [29]. These results confirm the introduction of the epoxy groups into the molecular structure of lignin as the result of an effective catalytic epoxidation reaction. A similar result can also be observed in the FTIR spectrum of the BTEAC-lignin epoxide sample, revealing that the catalysis of the lignin epoxidation can also be achieved with the BTEAC catalyst.

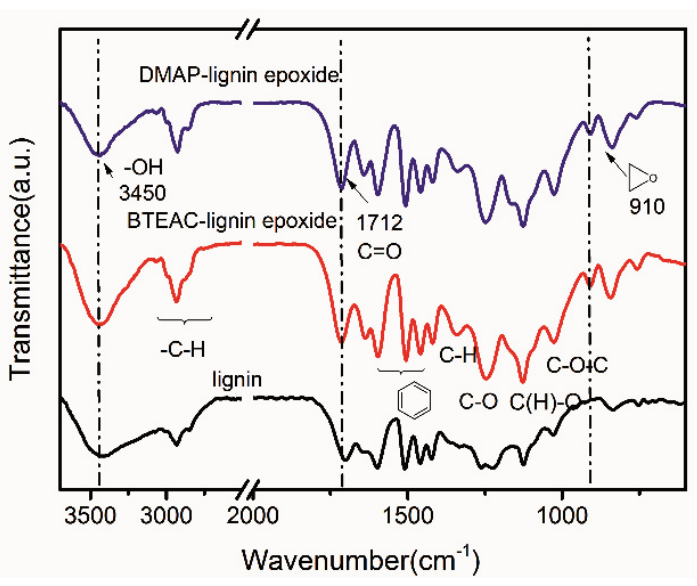

Figure 1. FTIR spectrum of the lignin, DMAP-lignin epoxide, and BTEAC-lignin epoxide. 
Table 4. Vibrational modes for FTIR absorbance peaks of lignin.

\begin{tabular}{cc}
\hline FTIR Band Position $\left(\mathbf{c m}^{-\mathbf{1}}\right)$ & Assignment \\
\hline $3450 \mathrm{~cm}^{-1}$ & stretching of $-\mathrm{OH}$ in hydroxyl group and carboxyl group \\
stretching of alkyl $\mathrm{C}-\mathrm{H}$ \\
3000, 2927, and $2846 \mathrm{~cm}^{-1}$ & stretching of $\mathrm{C}=\mathrm{O}$ in carboxyl group \\
1700 , and $1648 \mathrm{~cm}^{-1}$ & stretching of $\mathrm{C}=\mathrm{C}-\mathrm{C}$ bond in benzene ring \\
1600,1506 , and $1455 \mathrm{~cm}^{-1}$ & symmetric deformation of $\mathrm{C}-\mathrm{H}$ bond \\
$1338 \mathrm{~cm}^{-1}$ & stretching of $\mathrm{C}-\mathrm{O}$ in phenol group \\
$1260 \mathrm{~cm}^{-1}$ & stretching of $\mathrm{C}-\mathrm{O}$ in phenoxy group \\
$1222 \mathrm{~cm}^{-1}$ & stretching of $\mathrm{C}-\mathrm{O}$ in alkyl alcohol \\
$1130 \mathrm{~cm}^{-1}$ & stretching of $\mathrm{C}-\mathrm{O}$ in ether group \\
$1030 \mathrm{~cm}^{-1}$ & deformation of $\mathrm{C}-\mathrm{H}$ of benzene ring \\
\hline 846, and $748 \mathrm{~cm}^{-1}$ &
\end{tabular}

In order to further confirm the formation of the epoxy groups, the ${ }^{1} \mathrm{H}$ NMR spectra of the DMAP-lignin epoxide and BTEAC-lignin epoxide samples are provided in Figure 2. The characteristic protons of the main groups of lignin are assigned in the regions of $\delta_{\mathrm{H}}$ 3.50-4.00 ppm ( $\left.\mathrm{CH}_{3}-\mathrm{O}-\right)$, $\delta_{\mathrm{H}} 4.01-4.89 \mathrm{ppm}\left(-\mathrm{CH}_{2}-\mathrm{O}-\right), \delta_{\mathrm{H}} 6.14-8.00 \mathrm{ppm}$ (benzene ring), $\delta_{\mathrm{H}}$ 8.61-9.80 ppm (phenolic hydroxyl group), and $\delta_{\mathrm{H}}$ 12.04-13.00 ppm (-COOH). The signal peaks of carboxyl protons and phenolic protons disappear in the epoxidation lignin, and the signal peaks attributed to the epoxy group appear in the chemical shift range of $\delta_{\mathrm{H}}$ 2.60-2.90 ppm and $\delta_{\mathrm{H}}$ 3.20-3.50 ppm. These demonstrate the successful synthesis of the lignin epoxides. The earlier reports of Shou Zhao et al. support our results and show the same shift signal peaks of epoxy groups $[25,26]$.

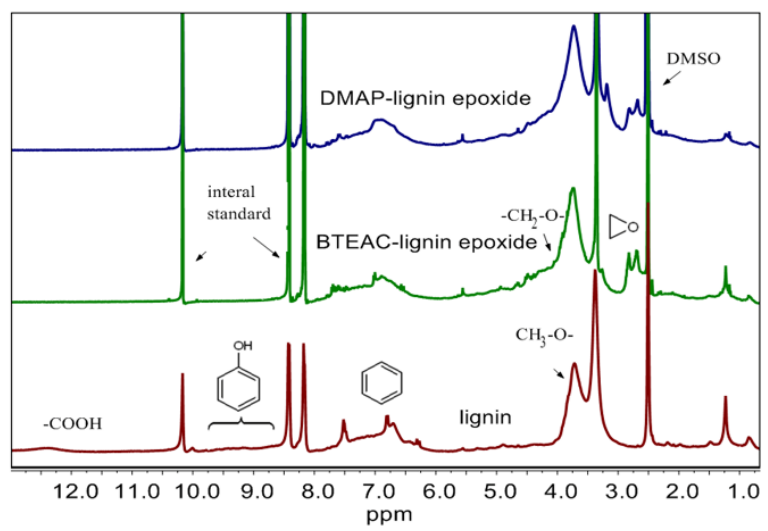

Figure 2. ${ }^{1} \mathrm{H}-\mathrm{NMR}$ spectra of the lignin, DMAP-lignin epoxide, and BTEAC-lignin epoxide.p-NBD was adopted as the internal standard, with the characteristic ${ }^{1} \mathrm{H}-\mathrm{NMR}$ peaks at $8.10-8.20,8.30-8.50$, and 10.10-10.20 ppm.

\subsection{Evaluation of the Performance of the Prepared DMAP-Lignin Epoxide and Its Cured Resin}

In addition to the epoxy value, the molecular weight and molecular weight distribution of the DMAP-lignin epoxide and BTEAC-lignin epoxide samples are also summarized in Table 5. Compared to the BTEAC-lignin epoxide, the DMAP-lignin epoxide possesses a lower molecular weight, narrower molecular weight distribution, and comparable epoxy value. Although DMAP and BTEAC have a similar epoxidized capability for lignin epoxidation, the DMAP catalyst can better control the molecular weight of the lignin epoxide as compared to BTEAC. The DMAP-lignin epoxide also exhibits better dispersibility and mobility during manufacturing processes that involve melting and curing. 
Table 5. The epoxy value, molecular weight, and Đ of the lignin epoxides.

\begin{tabular}{ccccc}
\hline \multirow{2}{*}{ Samples } & \multirow{2}{*}{ Epoxy Value (mmol/g) } & \multicolumn{3}{c}{ Molecular Weight } \\
\cline { 3 - 5 } & & $\mathbf{M}_{\mathbf{n}}$ & $\mathbf{M}_{\mathbf{W}}$ & $\mathbf{D}$ \\
\hline DMAP-lignin epoxide & 2.09 & 8244 & 17,085 & 2.07 \\
BTEAC-lignin epoxide & 2.16 & 9775 & 22,439 & 2.30 \\
\hline
\end{tabular}

The crosslinking density, storage modulus, and glass transition temperature $\left(T_{g}\right)$ of the three kinds of epoxy resins prepared by amine-based curing of the DMAP-lignin epoxide, BTEAC-lignin epoxide, and BADGE are summarized in Table 6. The order of the crosslinking density of these obtained resins is as follows: DMAP-lignin epoxide resin $<$ BTEAC-lignin epoxide resin $<$ BADGE resin. Such a sequence is consistent with the order of the epoxy value for the corresponding epoxides, namely the DMAP-lignin epoxide, BTEAC-lignin epoxide, and BADGE.

Table 6. Dynamic mechanical properties and crosslink density $(\rho)$ of the DMAP-lignin epoxide resin, BTEAC-lignin epoxide resin, and BADGE resin.

\begin{tabular}{|c|c|c|c|c|c|}
\hline \multirow[b]{2}{*}{ Sample } & \multicolumn{3}{|c|}{ Storage Modulus (MPa) } & \multirow[b]{2}{*}{$T_{\mathrm{g}}\left({ }^{\circ} \mathrm{C}\right)$} & \multirow[b]{2}{*}{$\begin{array}{c}\rho \\
\left(10^{-3} \mathrm{~mol} \cdot \mathrm{cm}^{-3}\right)\end{array}$} \\
\hline & $\begin{array}{c}\text { Glassy Region } \\
\text { at }-50{ }^{\circ} \mathrm{C} \\
\end{array}$ & $\begin{array}{c}\text { Glassy Region } \\
\text { at } 25^{\circ} \mathrm{C} \\
\end{array}$ & $\begin{array}{c}\text { Rubbery Region at } \\
T_{\mathrm{g}}+30^{\circ} \mathrm{C} \\
\end{array}$ & & \\
\hline BADGE resin & 11,300 & 8190 & 146.3 & 75 & 15.52 \\
\hline DMAP-lignin epoxide resin & 6460 & 1200 & 28.4 & 46 & 3.26 \\
\hline BTEAC-lignin epoxide resin & 5280 & 4286 & 43.8 & 90 & 4.47 \\
\hline
\end{tabular}

The variation of the storage modulus of the DMAP-lignin epoxide, BTEAC-lignin epoxide, and BADGE resin samples as a function of temperature is presented in Figure 3a. The storage modulus of the DMAP- and BTEAC-lignin epoxide resins are markedly lower than the BADGE resin at $-50{ }^{\circ} \mathrm{C}$, which is due to the much lower crosslinking density of the former (Table 6). When one compares the lignin-based resins, the DMAP-lignin epoxide resin shows a larger storage modulus as compared to the BTEAC-lignin epoxide resin, albeit with a lower crosslinking density. For the resin samples possessing similar crosslinking density, their packing structure can have a more significant impact on the storage modulus. The small molecular weight of DMAP-lignin epoxide resin can promote the packing density of resin (Figure S2), and further enhance the storage modulus in the glassy state. The influence of molecular weight on the dense packing and the storage modulus has been reported by Claudio Gioia et al., which is consistent with the conclusion in this paper [24].

(a)

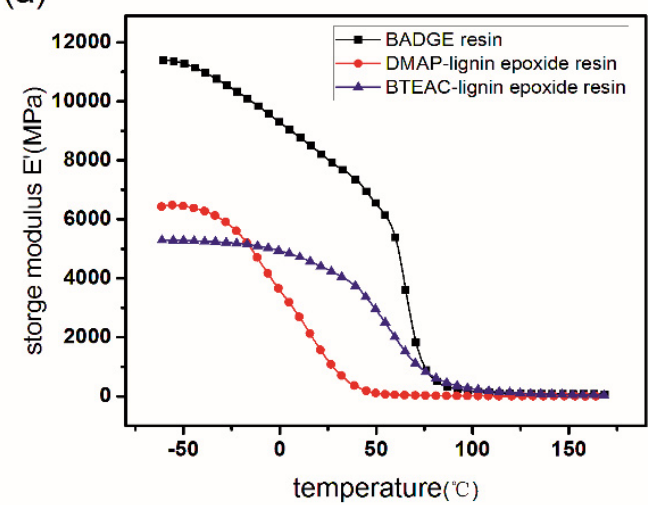

(b)

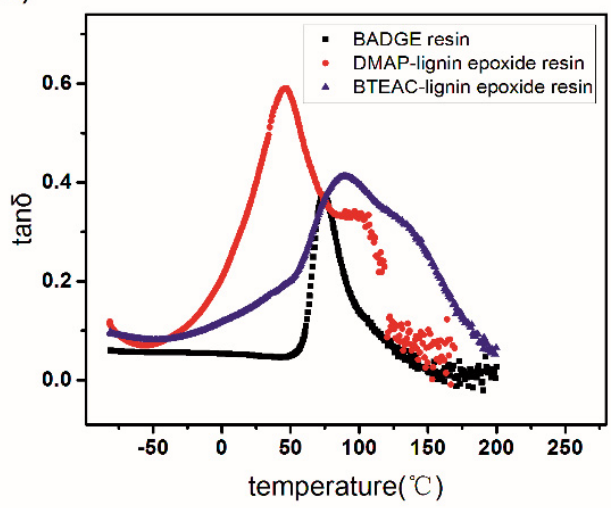

Figure 3. The storage modulus (a) and $\tan \delta(\mathbf{b})$ measured for the DMAP-lignin epoxide, BTEAClignin epoxide, and BADGE resins as a function of temperature. 
The order of the $T_{g}$ of the three kinds of epoxy resins is as follows: BTEAC-lignin epoxide resin $>$ BADGE resin $>$ DMAP-lignin epoxide resin. All of $T_{g}$ is larger than room temperature, making these kinds of resins applicable at room temperature. The $T_{g}$ of DMAP-lignin epoxide resin is notably smaller than the BTEAC-lignin epoxide resin and BADGE resin due to its lower crosslink density [30]. Such a low $T_{g}$ of the DMAP-lignin epoxide resin makes it promising for toughening the petroleum-derived epoxy resin (e.g., BADGE resin).

Although the BADGE resin has both high $T_{g}$ and high storage modulus (Figure $3 \mathrm{a}, \mathrm{b}$, and Table 6), it is still expected to achieve the co-curing composite of lignin epoxides with BADGE. For one thing, the lignin epoxide as an active macromolecule can strengthen the skeleton structure of BADGE resin by chemical reaction, and further improve the strength and toughness. For another, it is beneficial to promote the $T_{\mathrm{g}}$ and the crosslink strength of lignin epoxide resins and achieve a partial substitute for the BADGE.

In order to co-cure DMAP-lignin epoxide and BADGE, the compatibility between them should be the foremost problem to be resolved. The lignin epoxide is a polar macromolecular epoxide bearing hydroxyl groups, while BADGE is a viscous and aprotic polar epoxide with a low molecular weight. This discrepancy causes poor compatibility between them. In this study, the BDDGE diluent and the DMF solvent were employed to dissolve these two kinds of epoxides and improve their compatibility (see Experimental). After the lignin epoxide and BADGE had been dissolved, the DMF solvent was removed to facilitate the reaction between the epoxides and amine-based curing agent (in this case, TEAE). With the volatilization of the DMF solvent, the lignin epoxide was readily separated out of the BDDGE/DMF mixture because of its larger molecular weight. It is also worth noting that the higher content of DGEBA caused the lignin epoxide to be more easily separated out of the BDDGE/DMF mixed solution. Therefore, the lignin epoxide, with a larger molecular weight, exhibited a lower solubility during the manufacturing process with the lower content, resulting in the formation of the epoxy resin with obvious phase segregation. Unsatisfactory mechanical properties were subsequently measured. To ensure the good dissolution of the lignin epoxide before being cured, we added the TEAE for administering the curing reaction at room temperature once the DMF solvent was volatilized to a certain extent. The initial crosslinking reaction among the three kinds of epoxides, namely the lignin epoxide, BADGE, and BDDGE, resulted in the formation of an epoxy resin featuring a gel structure and integrated with a certain amount of the solvent that remained after the volatilization. Afterward, the solvent was further removed by heating and was accompanied by ring-opening polymerization. Finally, the epoxy resin was completely cured. Due to the lower molecular weight of the DMAP-lignin epoxide (as compared to that of the BTEAC-lignin epoxide), it was more resistant to be separated out of the BDDGE/DMF mixed solution, thus indicating its better solubility and processability.

The BADGE and DMAP- or BTEAC-lignin epoxide at a series of weight ratios were mixed into the BDDGE/DMF solution, resulting in the DMAP-lignin epoxide/BADGE (DB) and BTEAC-lignin epoxide/BADGE (BB) resins with various compositions. As you can see from Figure 4a, with the increase of weight of lignin epoxides, the tensile strength of composite resin first increased and then decreased. The tensile strength of DB60 was the highest, reaching up to $88.5 \pm 0.8 \mathrm{MPa}$. When the lignin epoxides substituted $80 \mathrm{wt} \%$ of BADGE, the tensile strength of DB80 resin still remained 76.3 $\pm 3.2 \mathrm{MPa}$. At this point, the lignin epoxide content in the resin was up to $58.0 \%$. The results showed that the composite resins with a high-biomass content still possess high tensile strength. This is because the DMAP-lignin epoxide participates in the crosslinking reaction of composite resin, changes the resin structure of composite resin without lignin epoxides (DB0), disperses the tensile stress effectively, and blocks the linear diffusion of cracks (Figure 5). Moreover, Continuous high curing temperature not only promotes complete crosslinking among the components but also enhances the binding of lignin epoxide itself. The high heating temperature is conducive to the increase of condensation between lignin fragments in composite resin, which in turn increases the bonding strength of the resin and improves the tensile strength 
of the resin. Although there have been reports on the effect of heating on the mechanical strength of lignin-based resins [13-15], the research is not systematic enough, and more studies on the heating effect on the properties of lignin-based resins should be conducted in the future. DB resin has better tensile strength than BB resin in the same mass ratio, which is due to its smaller molecular weight and narrower distribution of DMAP-lignin epoxide, resulting in better compatibility with BADGE and better homogeneity with each component of composite resin. With the ongoing rise of the lignin epoxide content, the elongation at break of DB resin first increased and then decreased similar to the change of its tensile strength, but the DB resin has the highest elongation at break with the $20 \%$ DMAP-lignin epoxide content (DB20) (Figure 4b). This result elucidates the fact that DB resin presents a better enhancement of toughening at lower biomass content.

(a)

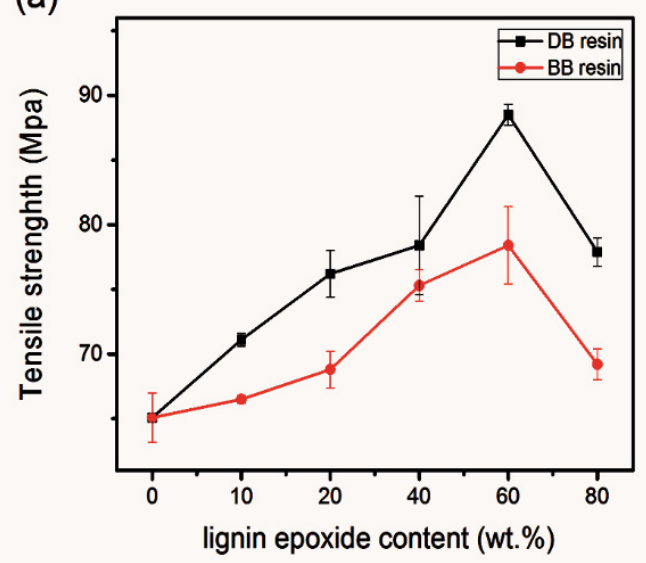

(b)

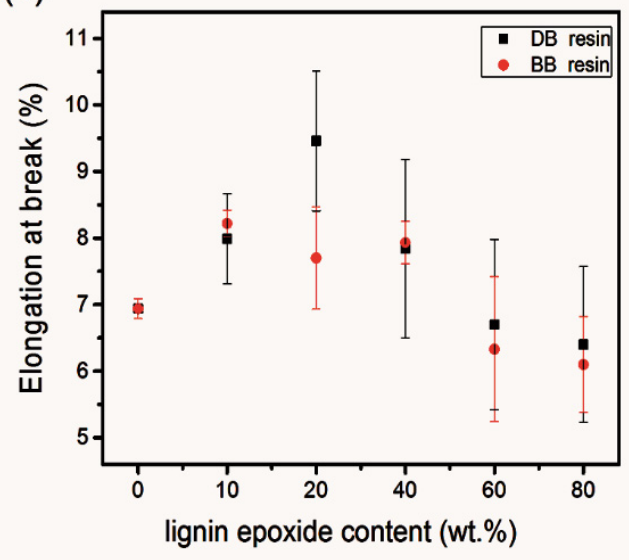

Figure 4. Tensile strength (a) and elongation at break (b) of the DB and BB resins with the different weight percentages of lignin epoxide. The lignin epoxide content is the weight percentages of DMAP-lignin epoxide replacement of BADGE.

After the tensile test, the fractured surface morphology of the DB resin was also studied by SEM observation; and the results are provided in Figure 5. No obvious phase interface can be observed in the composite resin, indicating that there is good homogeneity for each component of the composite resin. The DB0 without lignin epoxide is prone to form the brittle cracks of a radial pattern under the action of tensile stress (Figure 5a). When the lignin epoxide is added to the composite resin, the line crack propagation is blocked, forming a large number of regional areas with flabellate fracture surface morphology because of enhancement of the toughness (Figure $5 b$ ). When the content of the lignin epoxide compound is high, the crosslinking strength of the composite significantly decreases under the influence of the low epoxy value of lignin epoxide; and the tensile strength decreases accordingly, forming a fracture feature, like water-ripple morphology perpendicular to the tensile direction (Figure 5d). Only lignin epoxide and BADGE have a suitable mass ratio and uniform dispersion, and because the composite construct of their resin is stressed uniformly, the fracture surface morphology of the pretty turtle crack type will be formed. (Figure 5c). The BB resin presents a fractured surface morphology similar to the DB resin at the same weight percentage for lignin epoxide to BADGE (Figure S3). 

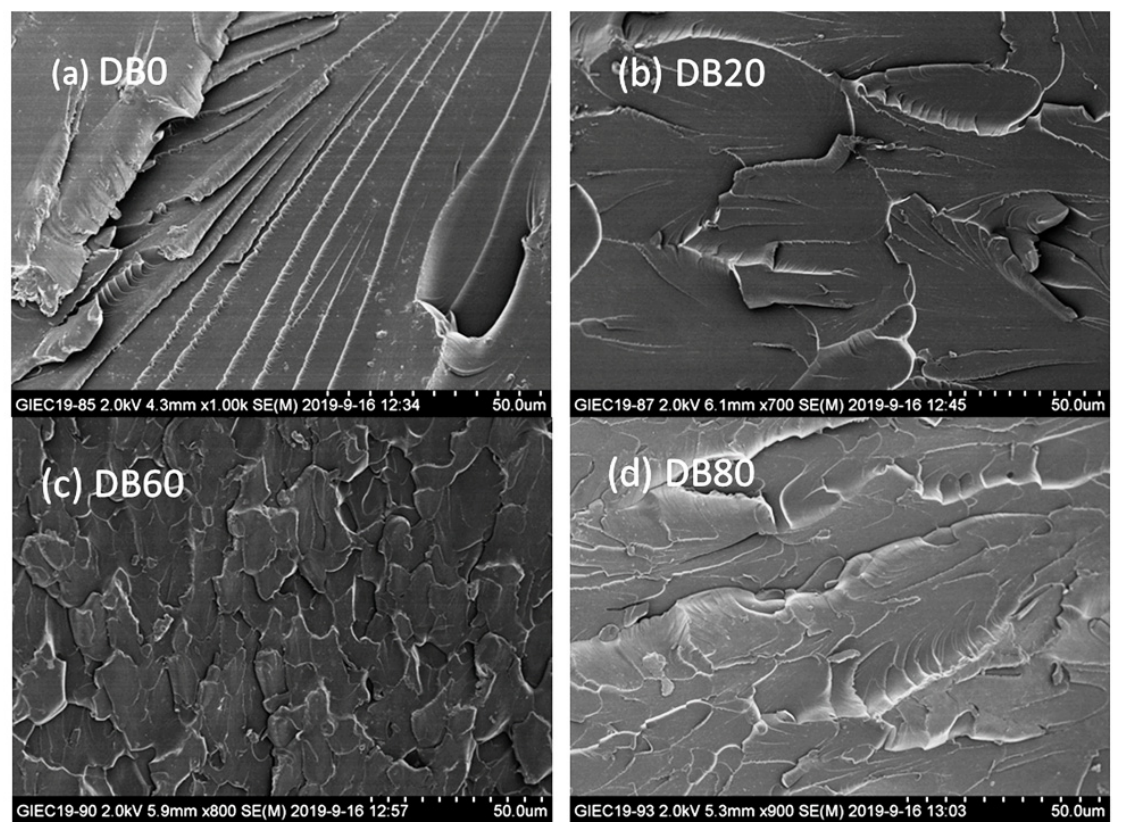

Figure 5. SEM images of the fractured surface of the DB0 (a), DB20 (b), DB60 (c) and DB80 (d) resin after tensile tests.

Since the DB and BB resins were prepared by co-curing of the lignin epoxide, BADGE, and BDDGE, their storage moduli are mainly affected by the factors in terms of crosslinking density, phase structure, and the molecular weight and structure of the epoxides $[11,24,31-34]$. The DB80 resin shows a higher storage modulus compared to the DB40 resin at a low temperature (i.e., $-50{ }^{\circ} \mathrm{C}$ ), as shown in Figure $6 \mathrm{a}$ and Table 7 . The crosslinking density can be decreased with the rise of the DMAP-lignin epoxide added amount; so the storage modulus should decrease. However, the DMAP-lignin-epoxide chain segment as the main component of DB80 resin, possessing a lower molecular weight, formed the more efficient packing of a dense 3D network structure with a smaller free volume. Moreover, the condensation reaction of the DMAP-lignin-epoxide chain segment in the curing by heating can also increase the compactness of the construct. This is why there is a $1461 \mathrm{MPa}-$ larger storage modulus of the DB80 resin as compared to that of DB40 at $-50{ }^{\circ} \mathrm{C}$ (Table 7). The low-temperature $\left(-50^{\circ} \mathrm{C}\right)$ storage modulus of the BB80 resin is close to that of its BB40 counterpart, but with a lower $260 \mathrm{MPa}$ difference (Table 7). This is because the poorer stacking structure of $\mathrm{BB}$ composite resin has sacrificed the storage modulus. Compared to the DMAP-lignin epoxide resin, the DB80 resin shows 1.5- and 2.7-fold increased storage moduli at -50 and $25^{\circ} \mathrm{C}$, respectively. These results demonstrate that the DB80 resin with a high-biomass content has a good storage modulus at room temperature by the co-curing of DMAP-lignin epoxide and BADGE. 
(a)

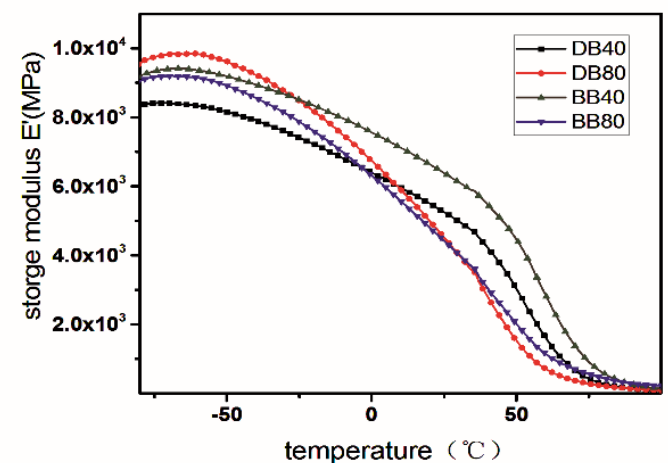

(b)

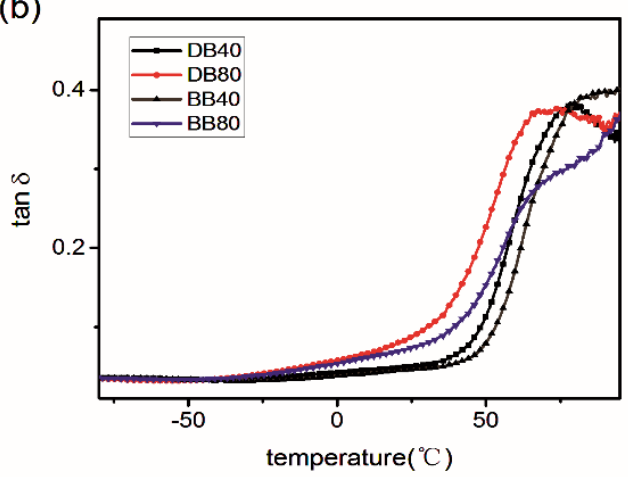

(c)

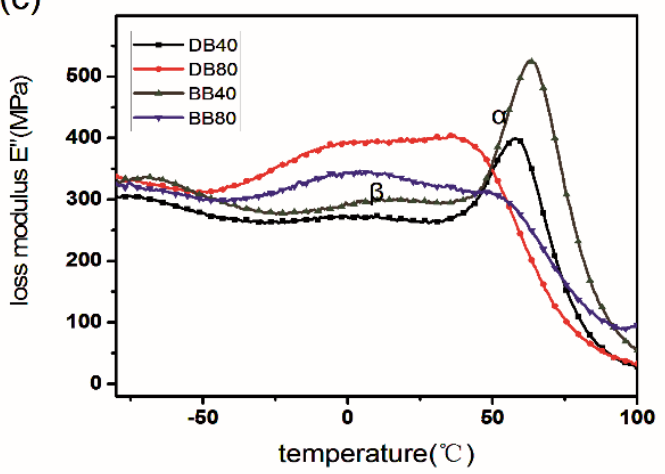

Figure 6. Plots of the storage modulus (a), $\tan \delta(\mathbf{b})$, and the loss modulus (c) as a function of temperature for various DB and $\mathrm{BB}$ resin samples with different added amounts of lignin epoxide.

Table 7. Storage modulus at the glassy region and transition temperatures for the DB40, DB80, BB40, and BB80 resins.

\begin{tabular}{ccccc}
\hline Sample & $\mathbf{E}^{\prime}$ at $-\mathbf{5 0}{ }^{\circ} \mathbf{C}$ & $\begin{array}{c}\text { 1st Transition } \\
\mathbf{T}_{\boldsymbol{\beta}} \text { from } \mathbf{E}^{\prime \prime}\end{array}$ & $\mathbf{E}^{\prime}$ at $\mathbf{2 5}{ }^{\circ} \mathbf{C}$ & $\begin{array}{c}\text { 2nd Transition } \\
\mathbf{T}_{\boldsymbol{\alpha}} \text { from } \mathbf{E}^{\prime \prime}\end{array}$ \\
\cline { 2 - 5 } & $\mathbf{( M P a )}$ & $\mathbf{(} \mathbf{C})$ & $\mathbf{( M P a )}$ & $\mathbf{(} \mathbf{C})$ \\
\hline DB40 & 8168 & 4.8 & 5239 & 59.1 \\
DB80 & 9629 & -4.6 & 4426 & 37.6 \\
BB40 & 9200 & 16.4 & 6336 & 62.9 \\
BB80 & 8940 & 4.2 & 4350 & 52.5 \\
\hline
\end{tabular}

The DB resins exhibit poor thermomechanical properties at temperatures higher than $100{ }^{\circ} \mathrm{C}$, and no intact peak can be discerned from the curve of the $\tan \delta$ vs. temperature, thereby making it difficult to obtain the $T_{g}$ (Figure $6 \mathrm{~b}$ ). Nevertheless, the $T_{g}$ values of the DB80 and DB40 samples are over $46^{\circ} \mathrm{C}$, which indicates that the co-curing DMAP-lignin epoxide with BADGE can improve the $T_{g}$ of the DMAP-lignin epoxide resin.

Since the multicomponent co-curing reaction was involved in the preparation of the DB resins, there are more than two characteristic peaks on the loss modulus curves. They mainly correspond to $\beta$ and $\alpha$ peaks as generated by the motion of the lignin epoxide and BADGE chain segments, respectively (Figure $6 c$ ). The increase in the lignin epoxide content intensifies $\beta$ peak and weakens $\alpha$ peak. Phase transition temperatures (namely $\mathrm{T}_{\alpha}$ and $\mathrm{T}_{\beta}$ ) are mainly affected by the crosslinking construct of the DB resin, and the increase in the lignin epoxide content makes the $\mathrm{T}_{\alpha}$ and $\mathrm{T}_{\beta}$ shift to lower temperatures (Table 7). The lower $\mathrm{T}_{\alpha}$ and $\mathrm{T}_{\beta}$ of the $\mathrm{DB}$ resin (vs. BB resin) likely results from the lower molecular weight of the DMAP-lignin epoxide as compared to that of the BTEAC-lignin epoxide.

The thermal stabilities of the $\mathrm{DB}$ and $\mathrm{BB}$ resins are further investigated, and the results are presented in Figure 7. Under an air atmosphere, the DB resin shows a variation tendency in the thermal degradation behavior similar to the BB resin (Figure 7a). There is a 
$5 \%$ weight loss at $250{ }^{\circ} \mathrm{C}$ for the $\mathrm{DB}$ resin; this is mainly due to the volatile components containing alkyl groups [35]. The thermal degradation occurring over the temperature range of $250-350{ }^{\circ} \mathrm{C}$ primarily arises from the alkyl ether chains. The thermal degradation over $250-350{ }^{\circ} \mathrm{C}$ begins to slow down, which can be associated with the alkyl groups connected to the phenyl oxygen occurring. With the ongoing temperature rise, the benzene ring structure starts to be thermally degraded, along with an increase in the thermal degradation rate. Finally, the DB resin is completely degraded at $650{ }^{\circ} \mathrm{C}[1,36]$. Under the $\mathrm{N}_{2}$ atmosphere, a large number of residues remain at $650{ }^{\circ} \mathrm{C}$ for the $\mathrm{DB}$ resin (e.g., $30 \%$ and $20 \%$ masses that remain for the DB80 and DB40 resins, receptively), as shown in Figure $7 \mathrm{~b}$. The increase of the DMAP-lignin epoxide content leads to an increased quantity of the residues, which indicates that the residual chain segments of the DMAP-lignin epoxide are more resistant to the thermal degradation in the $\mathrm{N}_{2}$ atmosphere [37]. Under the conditions of the same lignin epoxide content, fewer residues can be found for the DB resin as compared to that for the $\mathrm{BB}$ resin. This result is likely due to the lower molecular weight of the DMAP-lignin epoxide composition, which probably causes the resulting DB resin to expose a large, thermally liable surface.

(a)

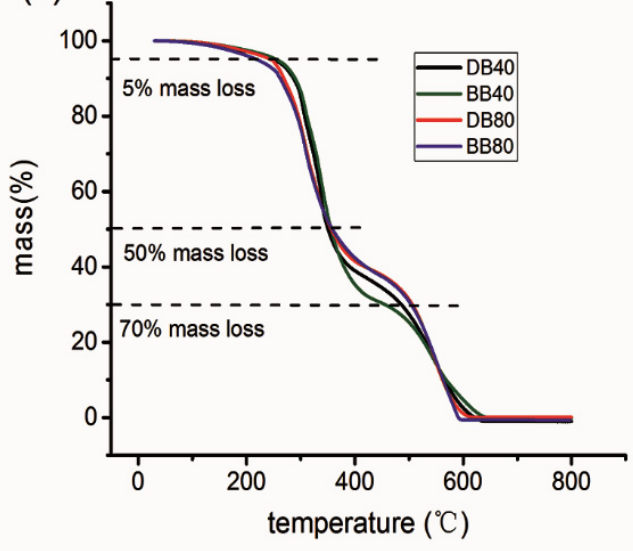

(b)

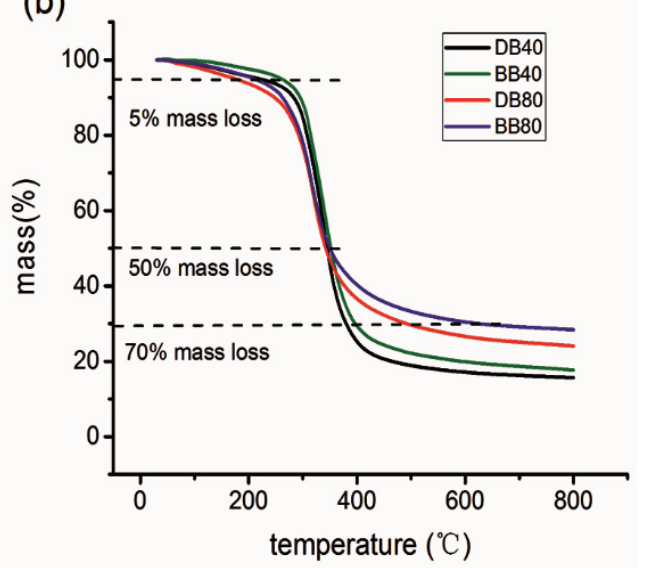

Figure 7. TG curves of the DB40, BB40, DB80, and BB80 resins under air (a) and $\mathrm{N}_{2}(\mathbf{b})$ conditions.

\section{DMAP-Lignin Epoxide Perspectives and Challenges for Practical Application}

In the face of the petroleum resource crisis and the awareness of ecological protection, it is very necessary to study and utilize lignin as a renewable, degradable, and environmentally-friendly polymer resource. Although there are many methods to degrade lignin into a small molecular state, the engineering utilization of macromolecular lignin is of great significance in reducing the cost of raw materials and enhancing the mechanical property of materials. DMAP catalyzes the epoxidation of macromolecular lignin, effectively controls the molecular weight of the epoxidation lignin, and then performs better in the molding process of the resin, forming a composite resin with high-biomass and high mechanical properties. The DMAP-lignin epoxide can be used in engineering plastics, functional composite, grouting, and other fields for development and utilization. However, it is still a big challenge to achieve the complete substitution of macromolecular lignin for petroleum-based raw materials to prepare the resin with strong mechanical properties and environmental friendliness. Because of the molecular steric hindrance of lignin epoxides, the bulk density of resin is affected; and the common solvents and curing agents will cause some environmental hazards. The control of both molecular weight and molecular structure of lignin should be further explored by the catalysts such as DMAP. At the same time, a green solvent such as ionic liquid should be developed for dissolving and curing the lignin epoxides and solving the existing environmental pollution problems. 


\section{Conclusions}

This study has demonstrated that the DMAP is an active and useful catalyst for the epoxidation of the lignin biomass with ECH. The resulting DMAP-lignin epoxide has an epoxy value of as high as $2.09 \mathrm{mmol} / \mathrm{g}$. Compared to the lignin epoxide produced with the BTEAC catalyst (corresponding to the BTEAC-lignin epoxide), the DMAP-lignin epoxide presents advantages in terms of structure, manufacturability, and performance of its resin. It has a smaller molecular weight, narrower molecular weight distribution, and better flowability during the manufacturing of the DMAP-lignin epoxide. Better low-temperature storage modulus and a more compact structure are shown for the corresponding DMAPlignin epoxide resin. The DB composite epoxy resins with different biomass content have different performance advantages. The DB20 resin has the best toughness; the DB60 resin has the highest tensile strength, reaching up to $88.5 \pm 0.8 \mathrm{MPa}$; the tensile strength of DB80 resin with $58.0 \mathrm{wt} \%$ lignin epoxide has $76.3 \pm 3.2 \mathrm{Mpa}$, and the storage modulus has $4426 \mathrm{Mpa}$ at $25^{\circ} \mathrm{C}$. The different types of composite resins meet the various mechanical performance requirements for practical applications. Therefore, such a low-cost biomassbased DMAP-lignin epoxide holds substantial potential for the partial substitution of the petroleum-based epoxy resin.

Supplementary Materials: Supplementary data to this article can be found online at https: / www. mdpi.com/2073-4360/13/5/750/s1. Figure S1: The typical structural units of lignin, and G, S, and $\mathrm{H}$ represent guaiacyl, syringyl, and $p$-hydroxypheny units, respectively. Figure S2: The structure morphology of both DMAP-lignin epoxide resin (a) and BTEAC-lignin epoxide resin (b). Figure S3: The SEM images of the fractured surface of the BB prepared with different addition amounts of BTEAC-lignin epoxide after tensile tests.

Author Contributions: Conceptualization, L.S., and H.P.; methodology, L.S.; investigation, L.S., Y.M., and P.L.; data curation, L.S.; validation, H.P., and L.S.; resources, L.S., Y.M., and P.L.; writ-ing-original draft preparation, L.S.; writing — review and editing, H.P., W.L., and Y.M.; project administration, H.P., and W.L.; funding acquisition, H.P. All authors have read and agreed to the published version of the manuscript.

Funding: This research was funded by the National Key Research and Development Program of China (2017YFD0601003), and GDAS' Project of Science and Technology Development (2020GDASYL-0102003).

Data Availability Statement: The data presented in this study are available on request from the corresponding author.

Conflicts of Interest: The authors declare no conflict of interest.

$\begin{array}{ll}\text { Abbreviations } \\ \text { DMAP } & \text { Dimethylaminopyridine } \\ \text { BTEAC } & \text { Benzyltriethylammonium chloride } \\ \text { BADGE } & \text { Bisphenol A diglycidyl ether } \\ \text { DB } & \text { DMAP-lignin epoxide/ BADGE } \\ \text { BB } & \text { BTEAC-lignin epoxide/BADGE } \\ \text { FRPs } & \text { Fiber-reinforced plastics } \\ \mathrm{M}_{\mathrm{n}} & \text { Number-average molecular weight } \\ \mathrm{M}_{\mathrm{w}} & \text { Weight-average molecular weight } \\ \mathrm{Ð} & \text { Molecular weight distribution } \\ \text { ECH } & \text { Epichlorohydrin } \\ \text { DMSO } & \text { Dimethyl sulfoxide } \\ \text { TETA } & \text { Triethylene teramine } \\ \text { DMF } & \text { Dimethyl formamide } \\ \text { BDDGE } & \text { Butanediol diglycidyl ether } \\ \mathrm{N}_{2} & \text { Nitrogen }\end{array}$




$\begin{array}{ll}\text { PTFE } & \text { Polytetrafluoroethylene } \\ \text { FTIR } & \text { Fourier transform infrared spectroscopy } \\ { }^{1} \mathrm{H} \text { NMR } & { }^{1} \text { H nuclear magnetic resonance } \\ \text { p-NBD } & \text {-Nitrobenzaldehyde } \\ \text { GPC } & \text { Gel permeation chromatography } \\ \text { PMMA } & \text { Polymethyl methacrylate } \\ \text { DMA } & \text { Dynamic mechanical analysis } \\ \text { E}^{\prime} & \text { Storage modulus } \\ \text { E }^{\prime \prime} & \text { Loss modulus } \\ \text { Tg } & \text { Glass transition temperature } \\ \rho & \text { Crosslink density } \\ \text { T } \alpha & \text { 1st Phase transition temperature } \\ \text { T } \beta & \text { 2nd Phase transition temperatures } \\ \text { G } & \text { Guaiacyl } \\ \text { S } & \text { Syringyl } \\ & \text { DMAP-lignin epoxide/ BADGE (DB) with DMAP-lignin epoxide replacement of } \\ \text { DB80 } & \text { 80 wt } \% \text { BADGE, while the other samples are named accordingly based on the weight } \\ & \text { percentage of lignin epoxide. } \\ \text { BB80 } & \text { BTEAC -lignin epoxide/ BADGE (BB) with BTEAC -lignin epoxide replacement of } \\ & \text { 80 wt } \% \text { BADGE, while the other samples are named accordingly based on the weight } \\ & \text { percentage of lignin epoxide. }\end{array}$

\section{References}

1. Liu, W.; Zhou, R.; Goh, H.L.S.; Huang, S.; Lu, X. From waste to functional additive: Toughening epoxy resin with lignin. ACS Appl. Mater. Interfaces 2014, 6, 5810-5817. [CrossRef] [PubMed]

2. Wang, Z.; Ganewatta, M.S.; Tang, C. Sustainable polymers from biomass: Bridging chemistry with materials and processing. Prog. Polym. Sci. 2020, 101, 101197. [CrossRef]

3. Adam, A.A.; Ojur Dennis, J.; Al-Hadeethi, Y.; Mkawi, E.M.; Abubakar Abdulkadir, B.; Usman, F.; Mudassir Hassan, Y.; Wadi, I.A.; Sani, M. State of the art and new directions on electrospun lignin/cellulose nanofibers for supercapacitor application: A systematic literature review. Polymers 2020, 12, 2884. [CrossRef] [PubMed]

4. Saratale, R.G.; Saratale, G.D.; Ghodake, G.; Cho, S.-K.; Kadam, A.; Kumar, G.; Jeon, B.-H.; Pant, D.; Bhatnagar, A.; Shin, H.S. Wheat straw extracted lignin in silver nanoparticles synthesis: Expanding its prophecy towards antineoplastic potency and hydrogen peroxide sensing ability. Int. J. Biol. Macromol. 2019, 128, 391-400. [CrossRef] [PubMed]

5. Kumar, P.; Maharjan, A.; Jun, H.-B.; Kim, B.S. Bioconversion of lignin and its derivatives into polyhydroxyalkanoates: Challenges and opportunities. Appl. Biochem. Biotechnol. 2019, 66, 153-162. [CrossRef]

6. Ganesh Saratale, R.; Cho, S.-K.; Dattatraya Saratale, G.; Kadam, A.A.; Ghodake, G.S.; Kumar, M.; Naresh Bharagava, R.; Kumar G.; Su Kim, D.; Mulla, S.I.; et al. A comprehensive overview and recent advances on polyhydroxyalkanoates (PHA) production using various organic waste streams. Bioresour. Technol. 2021, 325, 124685. [CrossRef]

7. Collins, M.N.; Nechifor, M.; Tanasa, F.; Zanoaga, M.; McLoughlin, A.; Strozyk, M.A.; Culebras, M.; Teaca, C.-A. Valorization of lignin in polymer and composite systems for advanced engineering applications-A review. Int. J. Biol. Macromol. 2019, 131, 828-849. [CrossRef] [PubMed]

8. Thakur, V.K.; Thakur, M.K.; Raghavan, P.; Kessler, M.R. Progress in green polymer composites from lignin for multifunctional applications: A review. ACS Sustain. Chem. Eng. 2014, 2, 1072-1092. [CrossRef]

9. Kalami, S.; Chen, N.; Borazjani, H.; Nejad, M. Comparative analysis of different lignins as phenol replacement in phenolic adhesive formulations. Ind. Crops Prod. 2018, 125, 520-528. [CrossRef]

10. Mahmood, N.; Yuan, Z.; Schmidt, J.; Xu, C. Preparation of bio-based rigid polyurethane foam using hydrolytically depolymerized Kraft lignin via direct replacement or oxypropylation. Eur. Polym. J. 2015, 68, 1-9. [CrossRef]

11. Sun, J.; Wang, C.; Stubbs, L.P.; He, C. Carboxylated Lignin as an Effective Cohardener for Enhancing Strength and Toughness of Epoxy. Macromol. Mater. Eng. 2017, 302, 1700341. [CrossRef]

12. Huang, F.; Liu, Y.Q.; Zhang, X.H.; Wei, G.S.; Gao, J.M.; Song, Z.H.; Zhang, M.L.; Qiao, J.L. Effect of elastomeric nanoparticles on toughness and heat resistance of epoxy resins. Macromol. Rapid. Commun. 2002, 23, 786-790. [CrossRef]

13. Kim, J.Y.; Hwang, H.; Oh, S.; Kim, Y.S.; Kim, U.J.; Choi, J.W. Investigation of structural modification and thermal characteristics of lignin after heat treatment. Int. J. Biol. Macromol. 2014, 66, 57-65. [CrossRef]

14. Cho, M.J.; Karaaslan, M.A.; Renneckar, S.; Ko, F. Enhancement of the mechanical properties of electrospun lignin-based nanofibers by heat treatment. J. Mater. Sci. 2017, 52, 9602-9614. [CrossRef]

15. Zhang, Y.; Wu, J.Q.; Li, H.; Yuan, T.Q.; Wang, Y.Y.; Sun, R.C. Heat treatment of industrial alkaline lignin and its potential application as an adhesive for green wood-lignin composites. ACS Sustain. Chem. Eng. 2017, 5, 7269-7277. [CrossRef]

16. Van de Pas, D.J.; Torr, K.M. Biobased epoxy resins from deconstructed native softwood lignin. Biomacromolecules 2017, 18, 2640-2648. [CrossRef] [PubMed] 
17. Ferdosian, F.; Zhang, Y.; Yuan, Z.; Anderson, M.; Xu, C. Curing kinetics and mechanical properties of bio-based epoxy composites comprising lignin-bised epoxy resins. Eur. Polym. J. 2016, 82, 153-165. [CrossRef]

18. Gioia, C.; Colonna, M.; Tagami, A.; Medina, L.; Sevastyanova, O.; Berglund, L.A.; Lawoko, M. Lignin-based epoxy resins: Unravelling the relationship between structure and material properties. Biomacromolecules 2020, 21, 1920-1928. [CrossRef]

19. Ferdosian, F.; Yuan, Z.S.; Anderson, M.; Xu, C. Synthesis of lignin-based epoxy resins: Optimization of reaction parameters using response surface methodology. RSC Adv. 2014, 4, 31745-31753. [CrossRef]

20. Kuo, P.Y.; Barros, L.D.; Sain, M.; Tjong, J.S.Y.; Yan, N. Effects of reaction parameters on the glycidyl etherification of bark extractives during bioepoxy resin synthesis. ACS Sustain. Chem. Eng. 2016, 4, 1016-1024. [CrossRef]

21. Asada, C.; Basnet, S.; Otsuka, M.; Sasaki, C.; Nakamura, Y. Epoxy resin synthesis using low molecular weight lignin separated from various lignocellulosic materials. Int. J. Biol. Macromol. 2015, 74, 413-419. [CrossRef] [PubMed]

22. Jiang, Y.; Ding, D.C.; Zhao, S.; Zhu, H.Y.; Kenttamaa, H.I.; Abu-Omar, M.M. Renewable thermoset polymers based on lignin and carbohydrate derived monomers. Green Chem. 2018, 20, 1131-1138. [CrossRef]

23. Li, W.; Zhang, Y.; Das, L.; Wang, Y.; Li, M.; Wanninayake, N.; Pu, Y.; Kim, D.Y.; Cheng, Y.-T.; Ragauskas, A.J.; et al. Linking lignin source with structural and electrochemical properties of lignin-derived carbon materials. RSC Adv. 2018, 8, 38721-38732. [CrossRef]

24. Gioia, C.; Lo Re, G.; Lawoko, M.; Berglund, L. Tunable thermosetting epoxies based on fractionated and well-characterized lignins. J. Am. Chem. Soc. 2018, 140, 4054-4061. [CrossRef] [PubMed]

25. Zhao, S.; Abu-Omar, M.M. Synthesis of renewable thermoset polymers through successive lignin modification using ligninderived phenols. ACS Sustain. Chem. Eng. 2017, 5, 5059-5066. [CrossRef]

26. Zhao, S.; Abu-Omar, M.M. Renewable epoxy networks derived from lignin-based monomers: Effect of cross-linking density. ACS Sustain. Chem. Eng. 2016, 4, 6082-6089. [CrossRef]

27. Flory, P.J. Molecular theory of rubber elasticity. Polymer 1979, 20, 1317-1320. [CrossRef]

28. Karumuri, S.; Hiziroglu, S.; Kalkan, A.K. Thermoset-cross-linked lignocellulose: A moldable plant biomass. ACS Appl. Mater. Interfaces 2015, 7, 6596-6604. [CrossRef] [PubMed]

29. Sasaki, C.; Wanaka, M.; Takagi, H.; Tamura, S.; Asada, C.; Nakamura, Y. Evaluation of epoxy resins synthesized from steamexploded bamboo lignin. Ind. Crops Prod. 2013, 43, 757-761. [CrossRef]

30. Stutz, H.; Illers, K.H.; Mertes, J. A Generalized theory for the glass-transition temperature of cross-linked and uncrosslinked polymers. J. Polym. Sci. Pol. Phys. 1990, 28, 1483-1498. [CrossRef]

31. Nicastro, K.H.; Kloxin, C.J.; Epps, T.H., III. Potential lignin-derived alternatives to bisphenol a in diamine-hardened epoxy resins. ACS Sustain. Chem. Eng. 2018, 6, 14812-14819. [CrossRef]

32. Patil, P.N.; Rath, S.K.; Sharma, S.K.; Sudarshan, K.; Maheshwari, P.; Patri, M.; Praveen, S.; Khandelwal, P.; Pujari, P.K. Free volumes and structural relaxations in diglycidyl ether of bisphenol-A based epoxy-polyether amine networks. Soft Matter 2013, 9 , 3589-3599. [CrossRef]

33. Tang, B.; Kong, M.; Yang, Q.; Huang, Y.; Li, G. Toward simultaneous toughening and reinforcing of trifunctional epoxies by low loading flexible reactive triblock copolymers. RSC Adv. 2018, 8, 17380-17388. [CrossRef]

34. Liu, T.; Han, B.; Zhang, L.; Wu, M.; Xing, A.; Miao, X.; Meng, Y.; Li, X. Environmentally friendly high performance homopolymerized epoxy using hyperbranched epoxy as a modifier. RSC Adv. 2016, 6, 14211-14221. [CrossRef]

35. Zhang, M.; Resende, F.L.P.; Moutsoglou, A.; Raynie, D.E. Pyrolysis of lignin extracted from prairie cordgrass, aspen, and Kraft lignin by Py-GC/MS and TGA/FTIR. J. Anal. Appl. Pyrolysis 2012, 98, 65-71. [CrossRef]

36. Liu, W.-J.; Jiang, H.; Yu, H.-Q. Thermochemical conversion of lignin to functional materials: A review and future directions. Green Chem. 2015, 17, 4888-4907. [CrossRef]

37. Morandim-Giannetti, A.A.; Agnelli, J.A.M.; Lancas, B.Z.; Magnabosco, R.; Casarin, S.A.; Bettini, S.H.P. Lignin as additive in polypropylene/coir composites: Thermal, mechanical and morphological properties. Carbohydr. Polym. 2012, 87, $2563-2568$. [CrossRef] 